Rev. Latinoam. Psicopat. Fund., São Paulo, 17(3), 450-468, set. 2014

http://dx.doi.org/10.1590/1415-4714.2014v17n3p450-5

\title{
Dor na psicanálise - física ou psíquica?*1
}

\author{
Natália Amendola Santos*2 \\ Ana Maria Rudge*3
}

A dor tem se apresentado contemporaneamente como um tema importante para a psicanálise. Um dos móveis desse interesse é a fibromialgia, descrita por profissionais da medicina como uma sindrome caracterizada pela dor crônica na ausência de lesões ou sinais de anormalidade na maquinaria biológica. Levanta-se o impasse - como pensar psicanaliticamente uma dor que é física? Algumas leituras são propostas, tais como associações da dor com o estado melancólico, com inibições psíquicas e com a hipocondria. A dor é tomada como expressão de uma vivência traumática e não simbolizada.

Palavras-chave: Dor, discurso freudiano, corpo, melancolia, alteridade, contemporâneo

${ }^{* 1}$ Estudo de Natália Amendola no mestrado em Psicologia Clínica da PUC-Rio, com orientação da segunda autora. O mestrado foi cursado com bolsa da Capes - Coordenação de Aperfeiçoamento de Pessoal de Nível Superior (Brasília, DF, Br).

*2 Pontifícia Universidade Católica do Rio de Janeiro - PUC-Rio (Rio de Janeiro, RJ, Br)

*3 Pontifícia Universidade Católica do Rio de Janeiro - PUC-Rio (Rio de Janeiro, RJ, Br) 


\section{ARTIGOS}

A dor é a prova de que nosso corpo é psíquico? Wittgenstein, em Investigações Filosóficas

Alguns questionamentos sobre manifestações dolorosas que incidem no corpo têm sido fonte de discussões não apenas no âmbito médico, mas em diferentes campos da saúde, justamente pela dificuldade em diagnosticar e tratar um sujeito que sente e sofre de uma dor que não apresenta qualquer indício orgânico.

Atualmente, o que vem se destacando são alguns estudos sobre a Fibromialgia, considerada uma síndrome reumatológica cuja principal característica é a dor musculoesquelética crônica e difusa que se associa à fadiga, à ansiedade, à depressão, à insônia e ao desânimo. Ela faz parte de um conjunto de síndromes com características bastante próximas que constituem um impasse clínico no que se refere à etiologia desconhecida. A fibromialgia, dor nos músculos e nos tecidos fibrosos, caracteriza-se também por ser difusa pelo corpo, possuindo certa proximidade com a depressão e a angústia. É justamente considerando tal proximidade que Berlinck (1999) considera que a psicanálise possa contribuir para uma maior compreensão desses fenômenos.

O diagnóstico de fibromialgia é eminentemente clínico, uma vez que não existem quaisquer alterações no aparato orgânico. Apesar de mecanismos fisiológicos não terem sidos estabelecidos, os especialistas apontam para fatores neuroendócrinos, genéticos e psicológicos envolvidos (Revista Brasileira de Reumatologia, 2010). Contudo podemos dizer que o fator etiológico é desconhecido (Revista Brasileira de Reumatologia, 2004).

O saber médico, por sua vez, executa o diagnóstico de fibromialgia por meio de um mapeamento anatomofísiológico do corpo e da doença. Parte do tratamento médico para esse mal-estar é medicação antidepressiva, entre outras técnicas que prometem o alívio da dor. Dessa forma, temos uma medicalização indiscriminada da dor e do sofrimento, o que evidencia que os pacientes não são acolhidos psiquicamente, sendo levados a experimentarem um alívio temporário, advindo da sensação de terem seu desamparo suavizado. Entretanto, em alguns casos, notamos a persistência da dor, mesmo quando se utilizam tratamentos com drogas farmacêuticas, o que chama a atenção para esse caráter enigmático e insistente da dor crônica.

A fibromialgia é caracterizada por uma duração maior do que o curso usual de uma doença aguda, o que em geral corresponde a persistência por mais de três meses. As dores crônicas mais frequentes se relacionam a doenças musculoesqueléticas e correspondem a modificações no sistema comportamental e funcional do sujeito. Alguns dados da Organização Mundial de Saúde (OMS) demonstram que a dor crônica atinge grande parte da população mundial, tornando-os incapacitados física e psiquicamente para a atividade profissional. Pesquisas e estudos indicam que 
$10 \%$ da população mundial sofre de dor crônica e difusa, a consequência disso são os altos investimentos em exames, tratamentos, remédios, enfim, abordagens que se mostram ineficientes talvez por ignorarem o sofrimento e o sintoma do paciente.

A fibromialgia é uma condição dolorosa crônica e generalizada, à qual se atribui a classificação de síndrome por englobar outras manifestações clínicas, como indisposição e distúrbios do sono. Esse mal-estar, com diagnóstico configurado bastante recentemente, apresenta uma riqueza de sintomatologia, porém sem que qualquer substrato físico seja encontrado.

Tal como o diagnóstico, a definição dessa síndrome também é motivo de controvérsia no campo médico (Quartilho, 2004; Eisinger, 2000) sendo apenas na década de 80 que a fibromialgia se caracterizou como síndrome de dor crônica, uma dor que é real e que necessita ser analisada.

Com definição nebulosa e diante da ausência de sinais no organismo que permitam um diagnóstico mais preciso, a dor crônica é também entendida como uma doença psicossomática e, por vezes, é lançada ao campo psi, convocando os profissionais da área a discutirem a respeito dessa patologia.

Mesmo que o tema da dor tenha sido pouco explorado pelos psicanalistas até recentemente, observamos, com certa frequência, apontamentos na literatura a respeito de pacientes que apresentam dores no corpo sem qualquer causa orgânica identificável pela visão da maquinaria médica. Ao nos depararmos com a insuficiência da medicina para tratar desta síndrome, como consequência, somos convocados, enquanto psicanalistas, a tentar responder sobre possíveis relações entre a dor e o tumultuado mundo pulsional do sujeito em questão.

Vale destacar que nesse aspecto, o corpo passa a ser meio de expressão da dor e do sofrimento, o que faz supor que estes encontrem empecilhos para se manifestarem no plano psíquico (Birman, 2003a). Portanto, cabe entender qual o destino para aquilo que não pode ser representado. Nesse aspecto, estamos em consonância com as ideias de Berlinck (1999), de que esses eventos podem seguir o destino do corpo como uma tentativa de se fazer representar.

Assim, se na modernidade freudiana o mal-estar se baseava nos conflitos psíquicos, em relação aos quais as interdições morais eram o centro da questão, parece-nos que atualmente o mal-estar na cultura se apresenta como dor, alojando-se especialmente no corpo, destituindo as categorias de pensamento e de linguagem como eixos ordenadores (Birman, 2009).

O corpo para a psicanálise não se reduz ao orgânico, ao contrário, ele é o lugar do qual emerge o circuito pulsional que visa satisfação por meio do prazer ou mesmo do desprazer. Assim, ao longo da obra freudiana, observamos que o corpo é teorizado de diversas formas, tais como: corpo da conversão histérica, corpo erógeno, corpo pulsional, corpo narcísico. Isto demonstra a importância fundamental do corpo na constituição de um aparelho psíquico. 
Baseados na contextualização abordada acima e instigados pela clínica psicanalítica, buscamos investigar uma manifestação somática sem indícios de causa orgânica e com um grave comprometimento do psiquismo, visto que é bastante incapacitante da vida ativa. Situada no campo marginal, entre psíquico e somático, a dor crônica, em sua dimensão enigmática, se configura como uma questão em aberto também para a psicanálise.

Nesse sentido, a dor crônica sem alterações orgânicas testemunha sobre uma profunda ligação entre físico e psíquico, e faz pensar sobre o que se apresenta num corpo pela via da sensação e do que seria possível de ser transmitido em palavras a respeito do sofrimento. Essa dor nos convoca pela via do poder da linguagem, visto que o registro médico e biológico pouco pode dizer ou fazer sobre ela. Assim, é preciso acessar o que há de enigmático no sujeito, o que apenas ele, na sua condição singular, poderia descrever, rompendo com categorias fixadas e universais.

Muito se tem dito que a contemporaneidade reserva aos sujeitos certa imprevisibilidade, como consequência de uma carência de referenciais simbólicos, e esta poderia ser considerada a marca que diferencia a modernidade de Freud da nossa contemporaneidade. Perturbações como síndrome do pânico, doenças psicossomáticas e depressões evidenciam que a grande marca das patologias atuais implica uma fragilidade dos recursos simbólicos. O que observamos como desdobramento, é que as perturbações psíquicas acabam se evidenciando, se expressando no corpo, pela dor, e na ação - a passagem ao ato tem adquirido certo privilégio como meio de domínio da regulação psíquica. Nesse contexto, destacamos as manifestações corporais de perturbações psíquicas, ou seja, o mal-estar expresso por meio de dores corporais.

Nossa hipótese, em se tratando de dor crônica, é de um funcionamento em que parece não estar em jogo recalque, sintoma ou elaboração psíquica. Não se trata das neuroses que foram teorizadas pelo pai da psicanálise, em que a estrutura do sintoma é a de uma formação de compromisso. Por essa razão, vale aproximar a dor crônica ao campo do não assimilável simbolicamente, da compulsão à repetição (Freud, 1920/1996k) em seu papel de tentativa de elaboração de um evento vivenciado como traumático. A partir disso, pensamos a dor como algo que se apresenta (Darstellung) sem um esboço de representação. Vale destacar que a denominação 'dor crônica' se originou da medicina, entretanto a qualidade "crônica" remete, especificamente para a psicanálise, a um outro sentido, apontando para a dimensão da insistência e para o caráter de repetição. A característica de ser crônica nos permite inferir certa proximidade entre esse tipo de dor e o registro da compulsão à repetição.

A ausência de uma representação psíquica ligada à dor sugere que ocorreu uma foraclusão de experiências traumáticas, que passarão a se manifestar apenas na dor, sem que ideias venham a se ligar a essa manifestação. Dessa forma, trabalhamos com uma clínica que nos convoca a interrogar a partir do corpo e numa escuta em que se possa ouvir o 'a mais' da dor, tratando-se então de um "psíquico 
que explode de maneira sempre ruidosa no registro somático. No seu limite, no entanto, a manifestação em pauta percorre fendas marcadamente antiexpressivas, caracterizando-se principalmente pelo silêncio" (Birman, 2003b, p. 1).

Com isso, como abordar, psicanaliticamente, uma produção sintomática centrada no somático? Sabemos que, se a psicanálise se depara com uma série de impasses clínicos quanto aos sintomas somáticos, isso se deu por conta de certo esquecimento de que o discurso freudiano se fundou a partir da articulação entre corpo e subjetividade, viabilizando a consolidação de uma diferença entre a noção psicanalítica de corpo e a de organismo. Um dos primeiros ensinamentos que o pai da psicanálise extrai dos sintomas histéricos, é que a erotização de um órgão subverte sua função orgânica, e esta deixa de funcionar a favor da conservação da vida.

Sabemos que a medicina se torna impotente diante das queixas de dores corporais, e que não dispõe de elementos capazes de regular esse mal-estar manifestado no corpo. Nesse sentido, cabe dirigir a palavra à psicanálise que, centrada no campo da fala e da linguagem, aposta que o inaudível possa se transformar em verbo.

A dor crônica se apresenta como uma forma do adoecer que não é capturada pela objetividade da medicina científica, já que o ato médico se manifesta como algo objetivado que visa à regulação das variáveis anatômicas e biológicas. A psicanálise aponta para que o projeto objetivista da medicalização é insuficiente, e visa restabelecer o lugar do sujeito diante de sua dor e de seu mal-estar.

Já no início do século XX, Freud lançou críticas à medicina positivista que se dirigiam à leitura objetivista dos sintomas e à despreocupação com o fato de que era sempre pela linguagem que o doente narrava sua enfermidade (Freud, 1905[1890]/1996h). São radicalmente distintas a narrativa do sofrimento que apresenta como referência o psíquico, e a narrativa da enfermidade que focaliza o somático. Se o mal-estar sempre comparece inscrito no discurso, o referente poderá ser tanto psíquico quanto somático.

Foi em um texto tardio de Freud, "Algumas lições elementares da psicanálise” (1940[1938]/1996u), que ele mais uma vez se refere à dicotomia cartesiana, tomando a posição já apresentada neste ensaio, a saber, a de que é estreita a relação entre fatores psíquico e o somático:

(...) não se pode desprezar por muito tempo o fato de que os fenômenos psíquicos são em alto grau dependentes das influências somáticas e o de que, por seu lado, possuem os mais poderosos efeitos sobre os processos somáticos. Se alguma vez o pensamento humano se encontrou num impasse, foi aqui. (p. 303)

A questão da complexa relação entre psicanálise e medicina, especialmente no que se refere à ruptura ocorrida entre esses dois campos do saber, foi trazida à baila pelos sintomas histéricos (Freud, 1893[1888-1893]/1996a; 1895[1893]/1996b; 1896/1996f), relacionados ao corpo representado, e que o modelo anatomoclínico 


\section{ARTIGOS}

da medicina não conseguia explicar. Se relacionarmos essas descobertas iniciais, relativas ao corpo tal como se apresenta na histeria, ao contexto contemporâneo, em que destacamos o corpo como cenário da manifestação de dor, notamos certa semelhança quanto à postura ainda adotada pelos diferentes campos do saber. Enquanto a medicina enxerga o corpo como uma maquinaria funcional, a psicanálise o percebe como uma complexa rede de relações que envolvem o interno e o externo. Toda a problemática que se refere às complexas relações que envolvem corpo e psiquismo, apresentada nos primórdios da psicanálise, é reeditada na contemporaneidade.

Como sabemos, a relação entre medicina e psicanálise foi marcada não só por rupturas, mas também por interlocuções (Birman, 2010) que contribuíram para caracterizar a atualidade desses dois campos do saber. Nesse aspecto, tanto medicina quanto psicanálise se apresentam e se constituem como formações discursivas que se inscreveram historicamente na modernidade (Foucault, 1969/1972).

A genialidade de Freud consistiu em demonstrar que os sintomas conversivos da histeria não seguem a lógica do corpo anatômico, mas sim a lógica do corpo representado (Freud, 1895[1893]/1996b; 1895/1996e). Eles refletiam o corpo do imaginário popular, do senso comum, e não ao mapeamento científico do corpo. Dessa forma, Freud teve seu encontro fatal com os impasses da histeria, constituindo, assim, as especificidades de um campo de saber e de uma prática clínica.

Vale destacar a diferenciação entre o organismo, como uma maquinaria estritamente orgânica e biológica, e o corpo, tal como o conhecemos na psicanálise: um corpo erógeno e simbólico, constituído a partir do investimento parental. O corpo do infante é inicialmente um corpo fragmentado e atravessado pelas pulsões autoeróticas (Freud, 1905/1996i). Segundo Freud, uma nova ação psíquica precisa ser acrescentada para que assim o narcisismo se constitua. É a nova ação psíquica que permite o esboço de uma unidade, uma representação inicial e precária do corpo (Freud, 1914/1996j).

Sendo assim, podemos marcar que Freud distingue corpo biológico e corpo psicanalítico, o que equivale dizer que a psicanálise faz a passagem da lógica da anatomia para a lógica da representação. O corpo, em psicanálise, é um corpo atravessado pela linguagem e pela alteridade. Demonstrar como os sintomas histéricos se moldam pelas forças do corpo representado, e não do corpo anatomopatológico, foi uma grande virada que contribuiu para a inauguração da psicanálise. Desse modo, Freud pôde esboçar algumas especificidades da escuta psicanalítica e iniciar todo um percurso que o levou à dinâmica do funcionamento inconsciente.

Mas não é só com relação ao sintoma histérico que a psicanálise tem a contribuir. Ela também amplia a visão do adoecer ao inserir implicações subjetivas nas perturbações orgânicas. Evidencia-se, assim, que a especificidade da contribuição psicanalítica reside na reflexão sobre a importância do inconsciente nas relações entre psíquico e somático. 
Retomando a questão da dor, notamos que, em "Luto e melancolia" (1917[1915]/1996o), Freud fala sobre a experiência dolorosa da perda, referindo-se a uma dor psíquica. Em contrapartida, ao abordar a hipocondria (Freud, 1914/1996j) que se caracteriza por uma intensa sensibilidade corporal e incômodas sensações físicas, Freud está se referindo a uma dor física. Entretanto, o que ressaltamos é que em ambas as situações de mal-estar, tanto na melancolia quanto na hipocondria, está em jogo um deslocamento da libido para o eu, caracterizando a retração narcísica da libido que está em jogo na dor, seja ela psíquica ou física.

Segundo Pontalis (2005), a construção do percurso freudiano sobre a dor parece nos levar ao encontro de uma teoria que denota certa "preferência pela escolha de uma ancoragem na dor em detrimento de uma mudança percebida como insuportável renúncia” (p. 266). O próprio título de seu livro - Entre o sonho e a dor — anuncia a posição do autor, que acredita que a clínica da atualidade é caracterizada por impasses no sonhar que remetem à alternativa entre a simbolização ou a presença intensa da dor.

É com a introdução do narcisismo (Freud, 1914/1996j), a retomada do trauma (Freud, 1920/1996p), a postulação da irrefreável pulsão de morte, a redefinição do masoquismo como primário (Freud, 1924/1996r), e a reação terapêutica negativa, que notamos uma reaproximação freudiana de questões outrora pensadas a partir do processo primário (Pontalis, 2005).

Os sonhos, após 1920, quando o paradigma das neuroses traumáticas orienta a construção da segunda tópica, não mais se limitam serem considerados como uma realização de desejos inconscientes, mas passam a ter também o papel de visar a elaboração simbólica do trauma pela compulsão à repetição (Rudge, 2002).

Para Birman (2009) a repetição do traumático em sonhos seria uma tentativa de transformar a dor num símbolo. O que resulta disso é o lugar privilegiado que o registro da dor passa a ocupar no psiquismo em contraposição ao do desejo, o que significa uma retomada do lugar que, no "Projeto...", a experiência de dor ocupava, simétrica e tão valorizada quanto a experiência de satisfação. Enquanto esta estaria na origem mítica do desejo primário ou pulsão, aquela estaria na origem mítica de uma força chamada de repulsa ou de defesa primária.

$\mathrm{O}$ que mais se destaca é que, desde o marco fundador da psicanálise, $A$ interpretação de sonhos (1900/1996g), a experiência de dor havia desaparecido, e Freud vinha teorizando o funcionamento de um circuito pulsional que operava segundo o princípio do prazer. Após a virada dos 20, com a inserção da ideia de pulsão de morte, e com a relativização do princípio do prazer que deixa de ser hegemônico no psiquismo, Freud passa a lidar com a força da pulsão desligada, com os efeitos de uma elaboração impossível de ser feita e com a ausência de simbolização. Estamos, então, diante de outro cenário, no qual as vicissitudes do trauma se fazem presentes e a compulsão à repetição é lançada na cena a fím de viabilizar a elaboração psíquica de um evento traumático (Freud, 1920/1996p). 


\section{ARTIGOS}

Todo esse contexto de 1920 se apresenta como uma espécie de retorno do recalcado da psicanálise freudiana, chamando a atenção para aspectos que até então não tinham sido acessados e elaborados pela teoria. Se Freud, desde o "Projeto..." (1950[1895]/1996d), valorizara tanto a vivência de satisfação como a vivência de dor e suas implicações, acabou por esquecer desta última ao redigir o capítulo 7 de $A$ interpretação dos sonhos (1900/1996g), no qual só se refere à experiência de satisfação e ao desejo primário, esquecendo a experiência de dor e a repulsa.

Mesmo sabendo que, no "Projeto..." (1950[1895]/1996d), os trilhamentos descritos por Freud podem ativar o neurônio secretor, que lança o desprazer no psiquismo quando as memórias são reativadas associativamente, parece-nos que a vivência de dor, assim como a força da repulsa a que ela dá origem, foi formulada com maior sucesso a partir de 1920, com o novo dualismo pulsional e a força da pulsão desligada.

Encontramos no Projeto (1950[1895]/1996d) uma explicação econômica para a dor, que se relaciona a um excesso de excitação que invade o sistema $p s i$, gerando aumento de tensão e descarga para o interior do corpo (uma descarga para o soma que é a contrapartida da sensação de angústia). Freud também vai ressaltar, no ensaio, que a quantidade (Q) acaba por produzir trilhamentos que deixam facilitações permanentes atrás de si no sistema psi (Freud, 1950[1895]/1996d). Baseado nesse fator, podemos inferir que as facilitações favorecem os mecanismos de dor e de repetição, uma vez que a quantidade tende a percorrer facilitações, evitando, assim, novos caminhos que impõem maior resistência. As facilitações que provocam a descarga dos neurônios secretores para dentro do psiquismo, fazem com que as memórias ligadas à dor não sejam investidas, ou seja, que não se possa inicialmente pensar ou lembrar experiências ligadas ao objeto hostil. É a isso que Freud chama repulsa ou defesa primária. Depois da inibição dessas passagens copiosas pelo Eu, a experiência de dor poderá entrar na cadeia associativa mediante um sinal de angústia (Freud, 1926/1996s) que caracteriza a vivência como algo a ser evitado.

O esquema do "Projeto..." apresenta, sob o nome de desejo (primário) o delineamento do que viria a ser a pulsão (Rudge, 1999). Isso nos permite o seguinte questionamento: tal como a pulsão se consolidou como um conceito fronteiriço entre somático e psíquico pela força do trabalho exigida à mente (Freud, 1915/1996k), a dor também poderia ser analisada, neste contexto de 1895, como um conceito fronteiriço? Dizemos isso porque no "Projeto..." não fica claro sobre que tipo de dor Freud está se referindo, a física ou a psíquica, ou se está desconsiderando, no seu campo de investigação, uma diferenciação clara entre ambas; isso embora a experiência de dor original tenha uma causa extrapsíquica, enquanto sua repetição, quando é deslanchada pela memória daquela experiência, tenha causa exclusivamente psíquica.

Nos textos "Rascunho G" (1895/1996c) e "Luto e melancolia" (1917[1915]/ 19960) Freud também nos fala sobre a dor, relacionando-a à perda de um objeto. Quando ele caracteriza melancolia e luto, faz referência à vivência dolorosa do 
luto que é atribuída à necessidade de abandono de uma posição libidinal (Freud, 1917[1915]/1996o). A retirada de investimento do objeto que foi perdido vem acompanhada de sofrimento, justamente pelo fato do eu ter que se separar do objeto, assim como pelo ódio contra o mesmo. É importante ressaltar que qualquer perda para o sujeito vai pressupor uma experiência de castração, uma vez que um vínculo, de alguma forma, teve de se romper. Nesses textos, Freud já está claramente se referindo a uma espécie de dor que é psíquica.

No texto "Recalque" (1915/19961), a experiência de dor é abordada a partir de um estímulo externo que, internalizado, provoca um aumento de tensão, adquirindo certa similaridade com uma pulsão, recebendo, então, o nome de pseudopulsão. Trata-se de uma dinâmica econômica que, obedecendo ao princípio de constância, tem por único objetivo fazer cessar o desprazer, de forma que não há nenhum outro prazer a ser alcançado. Lacan faz uma analogia entre o princípio do prazer e a homeostase, evidenciando que esse princípio não visa uma busca desenfreada do prazer, mas é uma tentativa de regulação pela qual se consiga algum prazer, evitando-se o desprazer excessivo.

Tal informação sugere que, em se tratando da experiência de dor nada da ordem do recalque, tampouco da formação de sintoma estaria em jogo, uma vez que o recalque não se efetua em situações nas quais a falta de satisfação de uma moção pulsional alcança um grau de tensão insuportável (Freud, 1915/19961, p. 152). Nesses casos, o organismo tem de recorrer a outro tipo de defesa, a saber, uma defesa externa advinda do outro. Entretanto é importante levar em conta que o recalque e os sintomas só se erigem diante de um conflito psíquico, ou seja, quando a satisfação de um desejo ou pulsão poderia convocar uma situação de dor. O conflito na teoria freudiana é fundamental, e nesta época tal concepção ainda não tinha sido conceituada de forma mais rigorosa. Por isso Freud se questionava ante o recalque de uma pulsão: por que a satisfação pulsional, que deveria provocar prazer, provoca desprazer? Dilema que foi superado apenas em 1926, com a construção mais rigorosa da metapsicologia do conflito e da angústia.

Em "Sobre o narcisismo: uma introdução" (1914/1996j), texto central da obra freudiana sobre o conceito psicanalítico de Eu, Freud, referindo-se à hipocondria, destaca que "uma pessoa atormentada por dor e mal-estar orgânico deixa de se interessar pelas coisas do mundo externo, na medida em que não dizem respeito a seu sofrimento (...) enquanto sofre, deixa de amar" (p. 89).

No que diz respeito à teoria da libido, isso implica dizer que, ao sentir dor ou algum tipo de mal-estar, o investimento libidinal abandona os objetos e se volta para o próprio eu do sujeito. Nesse caso, tanto a libido quanto o interesse da pulsão de autoconservação conservam o mesmo destino, tornando-se indistinguíveis, ou seja, nenhum conflito se dá entre eles. Tal ausência de conflito indica que a pulsão 


\section{ARTIGOS}

de autoconservação não está mais em oposição ao sexual, já que o investimento do $\mathrm{Eu}$, responsável pelo cuidado consigo, passa a ser também de ordem sexual.

Mais tarde, em "Além do princípio do prazer" (1920/1996p), Freud retorna ao tema da dor ao abordar a problemática do trauma, e diferencia aqueles que desenvolveram a neurose de guerra dos que sofreram algum tipo de lesão física. A neurose de guerra lhe parecia incidir mais fortemente naqueles que não se feriram no confronto. Essa observação sugere que a ferida no corpo pode assumir um status de representação, fornecendo algum sentido justamente por circunscrever a dor.

No texto "O eu e o isso" (1923/1966q), Freud apresenta a ideia de que o eu é corporal. $\mathrm{O}$ fato de que a superfície do corpo próprio constitui uma região da qual podem originar-se tanto sensações externas quanto internas, o leva a incluir a dor como um recurso que contribui para a formação de nossa representação do corpo.

Em "O problema econômico do masoquismo" (1924/1996r), ao observar que o aumento de excitação pode ser prazeroso, Freud concede que o aumento de tensão, como aspecto econômico, não corresponde necessariamente ao desprazer, sendo necessário inserir um fator qualitativo para abordar o processo. Dessa forma, a equiparação entre princípio do prazer e princípio de constância se vê questionada.

Entretanto, uma leitura atenta do texto de 1924 nos indica que Freud fala de impulsos que são satisfeitos pela punição, pelo sofrimento e pela submissão. Tudo isso são artifícios usados para que o sujeito não se depare com o desamparo de ter sido lançado na vida (Freud, 1930/1996t). A dor que aparece, a partir de então, é uma dor provocada por outrem ou uma condição causada pelo próprio sujeito como uma punição ou sacrifício a que o sujeito se submete. Portanto, esse texto nos serve como referência indicativa da dor na obra de Freud, destacando a fundamental importância da economia do masoquismo na experiência da subjetividade, tal como nos mostra a íntima relação entre masoquismo e Supereu.

No texto "Inibições, sintomas e angústia" (1926/1996s), Freud vai estabelecer sua segunda teoria da angústia. Além de uma nova leitura metapsicológica da angústia, no "Adendo C" desse texto, Freud vai nos falar sobre a dor, articulando-a ao luto e à angústia. Para tal, ele se utiliza do exemplo da reação do bebê diante de um estranho no lugar de sua mãe, a saber, uma reação de angústia.

Se entendermos a angústia como o sinal de uma discrepância entre o ambiente e a errância do humano, conforme nos esclareceu Berlinck (2003), o ser humano invariavelmente se constitui como um ser angustiado, necessitando, portanto, de recursos para lidar com a manifestação da angústia, e tanto o sintoma quanto a inibição são recursos para isso.

A angústia é, então, uma reação afetiva ao perigo que a perda representa, enquanto a dor é uma reação real ante à perda de objeto (Freud, 1926/1996s). Nas palavras do próprio Freud, “A dor é assim a reação à perda real do objeto, enquanto 
a angústia é a reação ao perigo da perda do objeto" (Freud, 1926/1996s, p. 165). É assim que ele insere o outro, enquanto presença ou ausência, na origem de toda dor, seja ela psíquica ou somática.

A dor crônica, como algo de ordem psíquica que se manifesta como uma descarga no corpo, não se configura como um sintoma para a psicanálise. Nas dores crônicas não estaria em jogo a complexa transformação de moções pulsionais, tampouco a construção de uma metáfora via retorno do recalcado.

Se tomarmos a nossa base inicial que associa a dor manifestada no corpo à melancolia, estaríamos trabalhando com dois aspectos, a saber, dois tipos de dores (física e psíquica) que, segundo o próprio discurso freudiano, apresentam-se como intrincadas, dificultando uma delimitação entre ambas.

Ao analisar a melancolia descrita em 1917 por Freud, notamos que nesta forma de mal-estar a angústia não se apresenta, destacando-se apenas o esvaziamento libidinal, as autoacusações e a disposição dolorosa. Se pensarmos nesses termos, identificamos que nos casos de dor crônica, a angústia também não se manifesta como tal. Nesse sentido, apoiados pela sutil descrição de Berlinck (2003) sobre inibição e sintoma, tendemos a pensar que a dor se aproxima muito mais de uma inibição do que de um sintoma propriamente analítico, ou mesmo da angústia. Essa ideia se complementa se pensarmos a inibição como uma forma de defesa contra a angústia. A inibição, nos casos de dor, entra em cena a fím de impedir que o sujeito sinta a angústia. Tal associação convoca-nos a pensar na dor como uma manifestação que não apresenta qualquer esboço simbólico, configurando-se apenas como uma queixa insistente e redundante.

A relação entre a dor crônica e a inibição de uma função do Eu leva à questão do manejo clínico no tratamento do paciente com dor crônica, sobretudo à questão da interpretação. Do ponto de vista clínico, não se interpreta uma manifestação que não remete a nenhum sintoma. Nesse caso, o manejo clínico se baseia na sustentação do analista enquanto presença e alteridade, para que assim alguma coisa do discurso do sujeito possa emergir a fim de estabelecer ligações psíquicas.

Pontalis (2005) estabelece uma articulação entre objeto perdido (Das Ding) e dor dizendo o seguinte:

Irremediavelmente perdido, mas sempre mantido, o objeto não poderia ser reencontrado pela via da representação, que torna presente um outro, a um só tempo mesmo e diferente. Lá onde há dor, é o objeto ausente, perdido, que está presente; o objeto presente, atual, que está ausente. De repente a dor da separação parece secundária em comparação com uma dor nua, absoluta. (p. 272)

No texto "Luto e melancolia" (1917[1915]/1996o), alguns impasses sobre a dor se apresentam como obstáculo teórico que ainda não foi ultrapassado, tal como nos aponta Freud, dizendo que "não podemos prosseguir (...) antes de obtermos melhor 


\section{ARTIGOS}

entendimento sobre a economia da dor, primeiramente a corporal e em seguida a anímica, análoga a ela" (Freud, 1917[1915]/1996o, p. 225). Não foi à toa que a palavra dor foi utilizada para caracterizar uma dor que é interna, mostrando que um sentimento de perda objetal pode equivaler a uma dor física. Freud diz: “(...) não pode ser para nada que o uso comum da palavra tenha criado a ideia de dor interna mental e tenha tratado o sentimento de perda de objeto como equivalente à dor física" (Freud, 1926/1996s, p. 166).

Portanto, baseados no próprio discurso freudiano, afirmamos que a passagem de uma dor corporal para uma dor psíquica é relacionada a uma transformação do investimento narcísico em investimento objetal, no qual a representação de um objeto toma o lugar do corpo investido pela quantidade de excitação (Ibid.). Nesse sentido, o componente doloroso que se refere à perda do objeto está associado ao luto. Sabemos que na melancolia o objeto não se deixa perder, fica incorporado, de forma que a experiência de perda não se efetua em luto; constitui-se assim uma espécie de vivência de um vazio e não de uma experiência de perda.

De toda forma, em ambas as situações, de dores físicas e psíquicas, corre um excesso de investimento que não pode ser descarregado, qual seja, da parte do corpo que emite dor (dor física) e do desejo pelo objeto perdido (dor psíquica). Assim, criam-se condições econômicas semelhantes, o que permite a Freud afirmar que a transição da dor física para a dor psíquica seria equivalente a uma mudança no investimento narcísico para o investimento objetal. Ele destaca ainda que, na dor corporal, existe a intervenção de um investimento elevado na representação do local dolorido, o que produz um efeito de esvaziamento do Eu. Sobre isso ele comenta que:

Quando há dor física, ocorre um alto grau do que pode ser denominado de investimento narcísico do ponto doloroso. Esse investimento continua a aumentar e tende, por assim dizer, a esvaziar o eu. Sabe-se que, quando os órgãos internos nos transmitem dor, recebemos representações espaciais e outras representações de partes do corpo que de maneira comum não são absolutamente representadas em ideias conscientes. Ademais, o fato marcante de que quando há um desvio psíquico ocasionado por algum outro interesse, mesmo as dores físicas mais intensas deixam de seguir (não devo dizer 'permanecem inconscientes' nesse caso) pode ser explicado por haver uma concentração de investimento no representante psíquico da parte do corpo que está emitindo dor. Penso ser aqui que encontramos o ponto de analogia que tornou possível levar as sensações de dor até a esfera mental, pois o intenso investimento de anseio está concentrado no objeto do qual se sente falta ou que está perdido (um investimento que aumenta com firmeza porque não pode ser apaziguado) cria as mesmas condições econômicas que são criadas pelo investimento da dor que se acha concentrada na parte danificada do corpo. (Freud, 1926/1996s, p. 166)

$\mathrm{Na}$ dor física há, então, um grande investimento do ponto doloroso, deixando, em contrapartida, o eu esvaziado. É possível então localizar a dor no registro psíquico, já que o investimento de anseio pelo objeto perdido cria as mesmas 
condições econômicas que as que ocorrem na dor física, quando os investimentos libidinais se concentram na parte danificada do corpo. $\mathrm{Na}$ dor física esse aumento de investimento se dá na parte do corpo que emite a dor, e na dor psíquica esse aumento de investimento se dá pelo anseio em relação ao objeto ausente.

Assim, a dor, tal como a angústia e o luto, liga-se a uma experiência de elevados níveis de investimento — em relação ao corpo e/ou ao objeto perdido - que não encontram via de descarga e por isso produzem sensação de desprazer. Nesse sentido, os aspectos econômicos em jogo seriam os mesmos, qual seja, um investimento nostálgico em relação ao objeto perdido (angústia) e um investimento que se concentra em determinada parte do corpo ferida (dor) (Ibid.).

Portanto, encontramos a dor, ao longo do discurso freudiano, como um excesso que apresenta consequências tanto no corpo quanto no psíquico. A característica da dor é a indiferenciação dos limites, tornando "pouco nítidas essas fronteiras" (Pontalis, 2005, p. 272). É assim que localizamos a dor entre o luto e a angústia, entre o investimento narcísico e o investimento objetal. Pontalis (2005) vai ressaltar que a dor seria uma espécie de acoplamento que engloba o dentro e o fora, a fantasia e a realidade, o tempo passado e o presente.

Freud tenta responder, em 1926, ao impasse que se apresentou desde o "Projeto..." (1950[1895]/1996d), o de compreender a relação entre dor física e dor psíquica. A dimensão econômica de ambas é o caminho apontado por Freud para melhor articulá-las. Com isso, observamos que a transferência da dor corporal para o domínio psíquico se relaciona ao direcionamento do investimento libidinal, a saber, depende da mudança do investimento narcísico para o investimento objetal.

De toda forma, podemos localizar a dor na obra freudiana como ligada a um excesso de tensão que apresenta consequências tanto no corpo quanto no psiquismo. É próprio da dor a indiferenciação dos limites e das fronteiras, sugerindo-nos que dor física e psíquica talvez sejam indissociáveis (Pontalis, 2005).

\section{Referências Bibliográficas}

Aisenstein, M.; Fine, A. \& Pragier, G. (Orgs.). (2002). Hipocondria. São Paulo: Escuta.

Alcides, R. (2009). Estratégias terapêuticas no tratamento da dor crônica: uma genealogia da clínica da dor. Dissertação de mestrado não publicada. Curso de Pós-graduação da Universidade do Estado do Rio de Janeiro, Centro Biomédico, IMS.

Antônio, S. F. (2001). Fibromialgia. Revista Brasileira de Medicina, 58, 215-24.

Bastos, L. A M. (1998). Eu-corpando: o ego e o corpo em Freud. São Paulo: Escuta.

Baszanger, I. (1998). Inventing pain medicine: from the laboratory to the clinic. New Brunswick, N.J.: Rutgers Univ. Press. 


\section{ARTIGOS}

Berlinck, M. T. (1999). A dor. In M. T. Berlinck (Org.). Dor (pp. 7-22). São Paulo: Escuta.

Berlinck, M. T. (2000). Psicopatologia fundamental. São Paulo: Escuta.

Berlinck, M. T. \& Fédida, P. (2000). A clínica da depressão: questões atuais. In M. T. Berlinck (Org.). Psicopatologia fundamental (pp. 73-91). São Paulo: Escuta.

Berlinck, M. T. \& Henckel, M. (2003, jan./jun.). Considerações sobre inibição e sintoma: distinções e articulações para destacar um conceito do outro. Estilos da Clínica, 8(14), 114-125.

Besset, V. L.; Gaspard, J. L.; Doucet, C.; Veras, M.; Cohen, R.H.P. (2010, dez.). Um nome para a dor: Fibromialgia. Revista mal-estar e subjetividade, 10(4), 1245-1269.

Birman, J. (1978) A psiquiatria como discurso da moralidade. Rio de Janeiro: Graal.

Birman, J. (1980) Enfermidade e loucura. Sobre a medicina das inter-relações. Rio de Janeiro: Campus.

Birman, J. (1997). Le corps et l'affect en psychanalyse - Une lecture critique du discours freudien. In: Che Vuoi? 7, 13-26.

Birman, J. (1998). A epopeia do corpo e a psicanálise. In L. A. M. Bastos (Org.). Eu corporando: o ego e o corpo em Freud (pp. 3-23). São Paulo: Escuta.

Birman, J. (1999a). Cartografias do feminino. São Paulo: Editora 34.

Birman, J. (1999b). A dádiva e o outro: sobre o conceito de desamparo no discurso freudiano. Physis: Revista Saúde Coletiva, 9(2), 9-30.

Birman, J. (2001). O sentido da retórica: sobre o corpo, o afeto e a linguagem em psicanálise. In: B. Bezerra Jr.; C. A. Plastino (Orgs.). Corpo, Afeto, Linguagem: a questão do sentido hoje. (pp. 173-198). Rio de Janeiro: Contra-Capa.

Birman, J. (2003a). Dor e sofrimento num mundo sem mediação. Revista Cultura, Rio de Janeiro, 95, 25-29.

Birman, J. (2003b). Corpos e formas de subjetivação. In F. Milnitzky (Org.). Desafios da clínica psicanalítica na atualidade (pp. 55-89). Goiânia: Dimensão.

Birman, J. (2006). Dor e sofrimento na contemporaneidade: sobre o sujeito na modernidade. Trieb, 5, 165-181.

Birman, J. (2007). Mal-estar na atualidade: a psicanálise e as novas formas de subjetivação. Rio de Janeiro: Civilização Brasileira.

Birman, J. (2009). Cartographie du contemporain. Espace, douleur et détresse dans l'actualité. Lyon: Parangon/Vs.

Birman, J. (2010). Discurso freudiano e medicina. In: J. Birman; I. Fortes \& S. Perelson (Orgs.). Um novo lance de dados: psicanálise e medicina da contemporaneidade (pp. 13-46). Rio de Janeiro: Companhia de Freud.

Bonica, J. J. (1990). The management of pain (2 ${ }^{\mathrm{a}}$ ed.). Philadelphia: Lea \& Febiger.

Canguilhem, G. (1978). O normal e o patológico. Rio de Janeiro: Forense-Universitária.

Delouya, D. (1999). A dor entre o corpo, seu anseio e a concepção de seu objeto. In M. T. Berlinck (Org.). Dor. São Paulo: Escuta.

Eisinger, J. (2000). Nouvelles approches diagnostiques des fibromyalgies. Lyon Medical, 36, 63-68.

Foucault, M. (1972). A arqueologia do saber. (Luiz Felipe Baeta Neves, trad.; Ligia Vassalo, rev.). Petrópolis: Vozes; Lisboa: Centro do Livro Brasileiro. (Trabalho original publicado em 1969).

Rev. Latinoam. Psicopat. Fund., São Paulo, 17(3), 450-468, set. 2014 
Foucault, M. (1977). Os corpos dóceis. In Vigiar e punir: nascimento da prisão (5ª ed.). Petrópolis: Vozes.

Freud, S. (1986). Contribution à la conception des aphasies. Paris: PUF. (Trabalho original publicado em 1891).

Freud, S. (1996). Edição Standard Brasileira das Obras Psicológicas Completas de Sigmund Freud. Rio de Janeiro: Imago.

Freud, S. (1996a). Alguns pontos para um estudo comparativo entre paralisias motoras e histéricas. In Edição Standard Brasileira das Obras Psicológicas Completas de Sigmund Freud (v. I). Rio de Janeiro: Imago. (Trabalho original publicado em 1893[1888-1893]).

Freud, S. (1996b). Comunicação preliminar. In Edição Standard Brasileira das Obras Psicológicas Completas de Sigmund Freud (v. II). Rio de Janeiro: Imago. (Trabalho original publicado em 1895[1893]).

Freud, S. (1996c). Rascunho G - melancolia. Publicações pré-psicanalíticas e esboços inéditos. In Edição Standard Brasileira das Obras Psicológicas Completas de Sigmund Freud (v. I). Rio de Janeiro: Imago. (Trabalho original publicado em 1895).

Freud, S. (1996d). Projeto para uma psicologia científica. Publicações pré-psicanalíticas e esboços inéditos. In Edição Standard Brasileira das Obras Psicológicas Completas de Sigmund Freud (v. I). Rio de Janeiro: Imago. (Trabalho original publicado em 1950[1895]).

Freud, S. (1996e). Estudos sobre a histeria. In Edição Standard Brasileira das Obras Psicológicas Completas de Sigmund Freud (v. II). Rio de Janeiro: Imago. (Trabalho original publicado em 1895).

Freud, S. (1996f). A etiologia da histeria - Primeiras publicações psicanalíticas. In Edição Standard Brasileira das Obras Psicológicas Completas de Sigmund Freud (v. III). Rio de Janeiro: Imago. (Trabalho original publicado em 1896).

Freud, S. (1996g). A psicologia dos processos oníricos - A interpretação dos sonhos - continuação. In Edição Standard Brasileira das Obras Psicológicas Completas de Sigmund Freud (v. V). Rio de Janeiro: Imago. (Trabalho original publicado em 1900).

Freud, S. (1996h). Tratamento psíquico. In Edição Standard Brasileira das Obras Psicológicas Completas de Sigmund Freud (v. VII). Rio de Janeiro: Imago. (Trabalho original publicado em 1905[1890]).

Freud, S. (1996i). Três ensaios sobre a teoria da sexualidade. In Edição Standard Brasileira das Obras Psicológicas Completas de Sigmund Freud (v. VII). Rio de Janeiro: Imago. (Trabalho original publicado em 1905).

Freud, S. (1996j). Sobre o narcisismo: uma introdução. In Edição Standard Brasileira das Obras Psicológicas Completas de Sigmund Freud (v. XIV). Rio de Janeiro: Imago. (Trabalho original publicado em 1914).

Freud, S.(1996k). As pulsões e seus destinos. In Edição Standard Brasileira das Obras Psicológicas Completas de Sigmund Freud (v. XIV). Rio de Janeiro: Imago.(Trabalho original publicado em 1915).

Freud, S. (19961). Recalque. In Edição Standard Brasileira das Obras Psicológicas Completas de Sigmund Freud (v. XIV). Rio de Janeiro: Imago. (Trabalho original publicado em 1915).

Freud, S. (1996m). O inconsciente. In Edição Standard Brasileira das Obras Psicológicas Completas de Sigmund Freud (v. XIV). Rio de Janeiro: Imago. (Trabalho original publicado em 1915). 


\section{ARTIGOS}

Freud, S. (1996n). Conferências introdutórias sobre psicanálise (continuação) - Conferência XVII: O sentido dos sintomas. In Edição Standard Brasileira das Obras Psicológicas Completas de Sigmund Freud (v. XVI). Rio de Janeiro: Imago. (Trabalho original publicado em 1917).

Freud, S. (1996o). Luto e melancolia. In Edição Standard Brasileira das Obras Psicológicas Completas de Sigmund Freud (v. XVI). Rio de Janeiro: Imago. (Trabalho original publicado em 1917[1915]).

Freud, S. (1996p). Além do princípio de prazer. In Edição Standard Brasileira das Obras Psicológicas Completas de Sigmund Freud (v. XVIII). Rio de Janeiro: Imago. (Trabalho original publicado em 1920).

Freud, S. (1996q). O eu e o isso. In Edição Standard Brasileira das Obras Psicológicas Completas de Sigmund Freud (v. XIX). Rio de Janeiro: Imago. (Trabalho original publicado em 1923).

Freud, S. (1996r). O problema econômico do masoquismo. In Edição Standard Brasileira das Obras Psicológicas Completas de Sigmund Freud (v. XIX). Rio de Janeiro: Imago. (Trabalho original publicado em 1924).

Freud, S. (1996s). Inibições, sintomas e angústia. In Edição Standard Brasileira das Obras Psicológicas Completas de Sigmund Freud (v. XX). Rio de Janeiro: Imago. (Trabalho original publicado em 1926[1925]).

Freud, S. (1996t). O mal-estar na civilização. In Edição Standard Brasileira das Obras Psicológicas Completas de Sigmund Freud (v. XXI). Rio de Janeiro: Imago. (Trabalho original publicado em 1930).

Freud, S. (1996u). Algumas lições elementares de psicanálise. In Edição Standard Brasileira das Obras Psicológicas Completas de Sigmund Freud (v. XXIII). Rio de Janeiro: Imago. (Trabalho original publicado em 1940[1938]).

Freud, S. (2004). As afasias. Buenos Aires: Nueva Visión. (Trabalho original publicado em 1891).

Garcia, C. (2010). Continuidade e ruptura no processo de constituição psíquica. In Entre o eu e o outro: espaços fronteiriços (pp. 29-46) Curitiba: Juruá.

Garcia, C. (2010). Trauma e narcisismo negativo: questões para a clínica contemporânea. In Entre o eu e o outro: espaços fronteiriços (pp. 65-76) Curitiba: Juruá.

Heymann, R. E. (2006). O papel do reumatologista frente à fibromialgia e à dor crônica musculoesquelética. Revista Brasileira de Reumatologia, 46(1). Recuperado em 11 set. 2013, de: <http:// www.scielo.br/scielo.php?script=sci_arttext\&pid=S048250042006000100001\&lang=pt $>$.

Heymann, R. E.; Paiva, E. S.; Helfenstein Jr., M.; Pollak, D. F.; Martinez, J. E.; Provenza, J. R. et al. (2010). Consenso brasileiro do tratamento da fibromialgia. Rev. Bras. Reumatol. 50(1), 56-66. Recuperado em 12 set. 2013, de: <http://www.scielo.br/scielo.php?script=sci_arttext\&pid=S0482-50042010000100006>.

Lambotte, M. C. (1997). O discurso melancólico: da fenomenologia à metapsicologia. Rio de janeiro: Cia. de Freud.

Laplanche, J. (1998). Problemáticas I: A angústia. São Paulo: Martins Fontes.

Laplanche, J. \& Pontalis, J. P. (1988). Vocabulário da psicanálise. São Paulo: Martins Fontes.

Leclaire, S. (1979). O corpo erógeno: uma introdução à teoria do complexo de Édipo. Rio de Janeiro: Jorge Zahar.

Rev. Latinoam. Psicopat. $\overline{\text { Fund., São Paulo, }}$ 17(3), 450-468, set. 2014 
Menkès, C. J. \& Godeaul, P. (2007). La fibromyalgie. Bull. Acad. Natle Méd. 191(1), 143-148. Recuperado em 11 set. 2013, de: <http://www.academie-medecine.fr/detailPublication. $\mathrm{cfm}$ ?idRub=26\&idLigne $=31>$.

Peres, U.T. (Org.) (1996). Melancolia. São Paulo: Escuta.

Perrier, F. (1993). A formação do psicanalista (Mirian Magda Giannella, trad.). São Paulo: Escuta.

Pontalis, J. B. (1991). Atualidade do mal-estar. In Perder de vista: da fantasia de recuperação do objeto perdido. Rio de Janeiro: Jorge Zahar.

Pontalis, J. B. (2005). Entre o sonho e a dor (Cláudia Berliner, trad.). Aparecida, SP: Ideias \& Letras (Coleção Psicanálise Século I).

Porte, J. M. (1999). La douleur: concept limite de la psychanalyse. Rev. Franç. Psychosom., 15, 149-166.

Provenza, J. R.; Pollak, D. F.; Martinez, J. E.; Paiva, E.S.; Helfenstein, M.; Heymann, R.; Matos, J. M. C. \& Souza, E. J. R. (2004, nov./dez.). Fibromialgia. Revista Brasileira de Reumatologia, 44(6). Recuperado em 10 set.2013 de <http://www.scielo.br/scielo.php?script=sci_arttext\&pid=S0482-50042004000600008\&ing=en\&nrm=iso $>$.

Quartilho, M. J. R. (2004). Fibromialgia: consenso e controvérsia. Acta Reumatologica Portuguesa, 29, 111-129.

Rudge, A. M. (1998). Pulsão: entre o corpo falante e o corpo mudo. In Pulsão e linguagem: esboço de uma concepção psicanalítica do ato. Rio de Janeiro: Jorge Zahar.

Rudge, A. M. (1999). O infantil na metapsicologia. Pulsional Revista de Psicanálise, São Paulo, XII(126), p. 13-29.

Rudge, A. M. (2002). Pour une meilleure comprehension d'Irma et du travail du rêve. Le Coq Héron, 169, 109-116.

Rudge, A. M. (2003, dez.). Trauma e temporalidade. Revista Latinoamericana de Psicopatologia Fundamental, São Paulo, VI(4), 102-116.

Rudge, A. M. (2006, jan./jun.). Pulsão de morte como efeito do supereu. Àgora, IX(1), 79-89.

Rudge, A. M. (2006). Traumas. São Paulo: Escuta.

Volich, R. M. (1999). De uma dor que não pode ser duas. In M. T. Berlinck (Org.). Dor. São Paulo: Escuta.

Volich, R. M. (2002). Hipocondria: impasses da alma, desafios do corpo. São Paulo: Casa do Psicólogo. (Coleção Clínica psicanalítica)

Zorzanelli, R. (2011). Novos sujeitos, novos corpos, novas configurações do sofrimento físico e mental. Palestra exibida em julho 2011 no Café Filosófico.

Weidebach, W. F. (2002, out./dez.). Fibromialgia: evidências de um substrato neurofisiológico. Revista Associação Médica Brasileira, 48(4), 291.

\section{Resumos}

(Pain in Psychoanalysis - physical or psychic?)

Pain has become an important theme for psychoanalysis. One of the reasons for this interest is the phenomenon of fibromyalgia, a syndrome described by medical 


\section{ARTIGOS}

professionals as characterized by chronic pain in the absence of lesions or signs of abnormality in the biological machinery. An impasse is brought up here - how to treat physical pain psychoanalytically? Interpretations are suggested, such as associations of pain with the melancholic state, with psychic inhibition or with hypochondria. Pain in these cases is taken as expression of a non-symbolized traumatic experience.

Key words: Pain, body, melancholy, otherness, contemporary

\section{(La douleur et la psychanalyse - physique ou psychique?)}

Actuellement, la douleur est présentée comme un thème majeur en psychanalyse. La fibromyalgie, l'une des causes de cet intérêt qu'on lui porte, a été décrite par les professionnels de médecine comme syndrome caractérisé par une douleur chronique sans lésions ou signes d'anomalies dans les mécanismes biologiques. L'impasse suivant est discuté: comment traiter, du point de vue de la psychanalyse, une douleur physique? Nous proposons quelques interprétations, telles que les associations de la douleur à l'état mélancolique, à l'inhibition psychique ou à l'hypochondrie. La douleur est définie comme l'expression d'une expérience traumatisante non symbolisée.

Mots clés: Douleur, corps, mélancolie, altérité, contemporain

(Dolor en el psicoanálisis - ¿físico o psíquico?

El dolor ha sido presentado en la actualidad como un tema importante para el psicoanálisis. Uno de los motivos de este interés es la fibromialgia, descrito por profesionales de la medicina como un síndrome caracterizado por dolor crónico en ausencia de lesiones o signos de anormalidad en la maquinaria biológica. La discusión es como pensar psicoanalíticamente un dolor que es fisico? Se proponen algunas lecturas, como las asociaciones del dolor con el estado melancólico, con las inhibiciones psíquicas y con la hipocondría. El dolor es tomado como una expresión de una experiencia traumática no simbolizada.

Palabras clave: Dolor, cuerpo, melancolía, alteridad, contemporáneo

(Schmerzen in der Psychoanalyse - physisch oder psychisch?)

In der Psychoanalyse ist der Schmerz ein Thema, das heute zunehmend an Bedeutung gewinnt. Ein ausschlaggebender Grund für dieses Interesse ist die Fibromyalgie, die von Fachleuten der Medizin als Syndrom bezeichnet wird, das sich durch chronischen Schmerz ohne zugrunde liegende Verletzung bzw. Anormalitäten des biologischen Apparates kennzeichnet. Dies führt in eine Sackgasse — wie ist ein physischer Schmerz psychoanalytisch $z u$ verstehen? In der Untersuchung werden verschiedene Betrachtungsweisen vorgeschlagen, wie z. B. die Assoziation von Schmerzen mit Melancholie, mit psychischen Hemmungen und mit Hypochondrie. Der Schmerz wird als Ausdruck einer traumatischen Erfahrung gesehen und nicht einer symbolischen Darstellung.

Schlüsselwörter: Schmerz, freudsche Sicht, Körper, Melancholie, Alterität, gegenwärtig 
Citação/Citatiom: Santos, N. A. \& Rudge, A. M. (2014, setembro). Dor na psicanálise - física ou psíquica? Revista Latinoamericana de Psicopatologia Fundamental, 17(3), 450-468.

Editor do artigo/Editor: Manoel Tosta Berlinck

Recebido/Received: 23.9.2013/9.23.2013 Aceito/Accepted: 30.11.2013/11.30.2013

Copyright: (C) 2009 Associação Universitária de Pesquisa em Psicopatologia Fundamental/ University Association for Research in Fundamental Psychopathology. Este é um artigo de livre acesso, que permite uso irrestrito, distribuição e reprodução em qualquer meio, desde que o autor e a fonte sejam citados / This is an open-access article, which permits unrestricted use, distribution, and reproduction in any medium, provided the original authors and sources are credited.

Financiamento/Funding: Esta pesquisa é financiada pela Capes - Coordenação de Aperfeiçoamento de Pessoal de Nivel Superior (Brasília, DF, Br) / This research is funded by Capes - Coordenação de Aperfeiçoamento de Pessoal de Nivel Superior (Brasília, DF, Br).

Conflito de interesses/Conflict of interest: As autoras declaram que não há conflito de interesses / The authors declare that has no conflict of interest.

\section{Natália Amendola Santos}

Psicóloga; Especialista em Psicologia Clínica pela CCE/Pontifícia Universidade Católica do Rio de Janeiro - PUC-Rio (Rio de Janeiro, RJ, Br); Mestre em Psicologia Clínica pela mesma universidade.

Rua Vice-Gov. Rubens Berardo, 175/702 bl. 2 - Gávea

22451-070 Rio de Janeiro, RJ, Br

e-mail: nataliamendola@yahoo.com.br

\section{Ana Maria Rudge}

Membro Psicanalista da Sociedade de Psicanálise Iracy Doyle - SPID (Rio de Janeiro, RJ, Br); Professora do Mestrado em Psicanálise, Saúde e Sociedade da Universidade Veiga de Almeida (Rio de Janeiro, RJ, Br); Professora Colaboradora do Programa de Pós-Graduação em Psicologia da Pontifícia Universidade Católica do Rio de Janeiro - PUC-Rio (Rio de Janeiro, RJ, Br), Pesquisadora do Conselho Nacional de Desenvolvimento Científico e Tecnológico - CNPq (Brasília, DF, Br), Pesquisadora e Membro Fundador da Associação Universitária de Pesquisa em Psicopatologia Fundamental (São Paulo, SP, Br).

Rua Major Rubens Vaz, 514/902 - Gávea

22470-040 Rio de Janeiro, RJ, Br

e-mail: ana.rudge@uol.com.br 